\title{
Gas-phase acidity of sulfonamides: implications for reactivity and prodrug design
}

\author{
J. R. B. Gomes* and P. Gomes \\ Centro de Investigação em Química, Departamento de Química, Faculdade de Ciências da Universidade do Porto, \\ Rua do Campo Alegre 687, P-4169-007 Porto, Portugal
}

Received 25 October 2004; revised 7 January 2005; accepted 12 January 2005

\begin{abstract}
A computational study at the density functional theory level was performed on bioactive and model sulfonamides with the aim of determining the factors affecting the acidity of the sulfonamido group. The effects of introducing different substituents at either the para-aryl or the $\mathrm{N}^{1}$-sulfonamide positions were independently analyzed. A linear correlation was found between sulfonamide acidity and the Hammett constants or charge of the $\mathrm{SO}_{2}$ group of substituents at the para-aryl position. Most $\mathrm{N}^{1}$-substituents were taken from bacteriostatic sulfonamide structures and presented a more complex behavior, possibly due to a conjugation of steric and electronic factors. In the latter situation, sulfonamide acidity and the charge of the $\mathrm{SO}_{2}$ group were not linearly correlated. Interestingly, the acidity of the sulfonamido group was found to be correlated with the reactivity of sulfa drugs towards acylating agents. The implications for the design of suitable sulfonamide prodrugs are discussed.

(C) 2005 Elsevier Ltd. All rights reserved.
\end{abstract}

\section{Introduction}

The characterization of sulfonamides as chemotherapics is more than half a century old. ${ }^{1}$ Since then, the sulfonamido group $-\mathrm{SO}_{2} \mathrm{NH}-$ has been found as a key structural motif shared by a large number of bioactive compounds, spanning a wide variety of biological effects, such as antimicrobial activity, specific enzyme inhibition, hormone regulation, among others. ${ }^{2}$ The most popular sulfonamides are $p$-aminobenzensulfonamides, or sulfanilamides (1), which are bacteriostatic due to their resemblance to $p$-aminobenzoic acid (PABA, 2), used by bacteria in the biosynthesis of the folic acid required for their growth. ${ }^{3}$

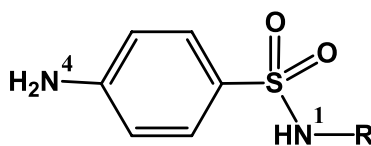

1

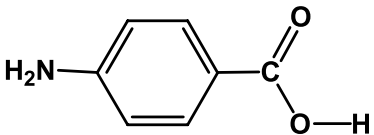

2
Most bacteriostatic sulfonamides are characterized by a $p$-aminoaryl moiety and structural diversity has been obtained basically by variation of the R-group linked to

Keywords: Acylation; Amino acid; Bioactive; Density functional theory; Gas-phase acidity; Peptide; Prodrug; Sulfonamide.

* Corresponding author. Tel.: +351 226081814; fax: + 351 226082959; e-mail: jrgomes@fc.up.pt the $\mathrm{N}^{1}$ atom of the sulfonamido group. Generally, this $\mathrm{R}$ group is a heterocyclic structure that renders the compound several times more active than the original sulfanilamide $(\mathrm{R}=-\mathrm{H})$. In the early days of sulfonamide therapy, experimental studies by Bell et al. ${ }^{4}$ Kumler et al. ${ }^{5,6}$ and, 20 years later, Seydel, ${ }^{7}$ have been devoted to the analysis of stereoelectronic factors that could be related to bacteriostatic activity, paying special attention to the role of the acidity of the sulfonamido group. ${ }^{4,7}$ These studies suggested that bacteriostatic activity is favored by decreased sulfonamide acidity (larger $\Delta G^{\circ}$ values), which was confirmed in a very recent theoretical work published by Soriano-Correa and co-workers. ${ }^{8}$ Also, distinct therapeutical effects are often associated to different acidity ranges, as illustrated by the higher acidity of antiglaucoma sulfas when compared to their cancerostatic counter parts. ${ }^{9}$ Thus, it seems that the acidity of the sulfonamido group, and factors affecting it, are key features ruling the physico-chemical properties that modulate the sulfonamide bioactivity.

Due to the well-known problems of sulfonamide therapy, especially those related to growing bacterial resistance, adverse effects and low bioavailability, ${ }^{10-12}$ we have been working on the synthesis of $\mathrm{N}^{1}$-acyl and $\mathrm{N}^{4}$-acylsulfanilamides as potential prodrugs of antimalarial sulfonamides. These antimalarials were acylated with amino acids and dipeptides, which are interesting carriers for drug delivery in vivo. Dipeptide carriers have several advantages, since they are non-toxic, non-immunogenic and can trigger the 
intestinal oligopeptide transporter, favoring prodrug absorption in the gastro-intestinal tract. ${ }^{13-16}$ Also, dipeptide-based prodrugs can be activated by a strictly chemical process, an intramolecular cyclization to a 2,5-diketopiperazine, and, thus, not subject to biological variability. ${ }^{13,17-19}$ The development of efficient sulfonamide prodrugs is a priority in medicinal chemistry, since sulfonamides such as sumatriptan (a 5-HT 1 agonist for migraine treatment), acetazolamide (antiglaucoma carbonic anhydrase inhibitor) or nimesulide (anti-inflamatory COX-2 inhibitor) still suffer from several problems related to low bioavailability or serious adverse effects. ${ }^{10,11,20}$ Further, N-acylated and amino acid based sulfonamides are emerging as potential antiviral and antitumoral drugs ${ }^{21,22}$ and, thus, a detailed description of $\mathrm{N}$-acylsulfonamides is mandatory.

In a previous experimental work, we found that sulfanilamide acylation was regiosselective (Scheme 1) and that the degree of regiosselectivity and reactivity depended of the drug employed. ${ }^{13}$ This prompted us to perform a brief computational analysis of the geometrical and thermodynamic factors ruling the acylation reactions between amino acid glycine and four sulfanilamides, in order to explain our experimental findings. ${ }^{13} \mathrm{We}$ now wish to present an extensive computational study of the gas-phase acidity of both bioactive and model sulfonamides, in order to evaluate the relevance of this property on their reactivity towards acylating agents. Implications of the present study for prodrug design will be discussed.

\section{Computationals details}

In the present work, the density functional theory based B3LYP three-parameter hybrid method proposed by Becke $^{23}$ was used for all the calculations. These computations were performed by means of the GAMESS-US ${ }^{24}$ and Gaussian $98^{25}$ suites of programs. The B3LYP method comprises an exchange-correlation functional that mixes the non-local Fock exchange with the gradient-corrected form of Becke ${ }^{23}$ and adds the correlation functional proposed by Lee et al. ${ }^{26}$ The use of the B3LYP method is known to be an excellent computational choice both to obtain geometric and thermodynamic data. ${ }^{27-29}$ In fact, the three $a, b$ and $c$ parameters in this hybrid approach were determined by fitting to experimental thermochemical data which include atomization energies, ionization energies, proton affinities and atomic energies of a large set of molecules. ${ }^{23}$ Very recently, several different thermochemical properties have been computed at the B3LYP level of theory and the results obtained compare excellently with available experimental data. $^{29,30-36}$

In the DFT calculations, the geometry optimization runs were performed without symmetry constraints for all compounds considered and the atomic electronic density of all atoms was described by the standard 6-31+G(d) basis set. The calculation of frequencies was performed to ensure that a minimum is located and also to correct total energies by including the Zero-Point Energies, ZPE, as well as translational $\left(H_{\mathrm{T}}\right)$, rotational $\left(H_{\mathrm{R}}\right)$ and vibrational $\left(H_{\mathrm{V}}\right)$ contributions to the enthalpy at $T=298.15 \mathrm{~K}$. Then, a single-point energy calculation $\left(E_{0}\right)$ was performed at the B3LYP/6-311+G(2d,2p) level of theory on the 6-31+G(d) optimized geometries. The thermally corrected enthalpy of species A is calculated as:

$$
\begin{aligned}
& H(\mathrm{~A}, 298.15 \mathrm{~K})=E_{0}(\mathrm{BL})+\mathrm{ZPE}(\mathrm{BS})+H_{\mathrm{T}}(\mathrm{BS}) \\
& \quad+H_{\mathrm{R}}(\mathrm{BS})+H_{\mathrm{V}}(\mathrm{BS})+R T
\end{aligned}
$$

where BL and BS stand for basis large $(6-311+\mathrm{G}(2 \mathrm{~d}, 2 \mathrm{p}))$ and basis small $(6-31+\mathrm{G}(\mathrm{d}))$, respectively, and $R T$ results from the $P V$ term.

From previous experience, the use of this combined strategy, B3LYP/6-311+G(2d,2p)//B3LYP/6-31+G(d) approach, yields identical results to that obtained from full-optimization and frequencies calculations performed at the B3LYP/6-311+G(2d,2p) level, ${ }^{31-33}$ i.e. where all terms in equation (1) are computed using the large basis. In these works, the combined approach was tested for several different thermodynamic properties, such as enthalpies of formation, bond dissociation enthalpies, gas-phase acidities

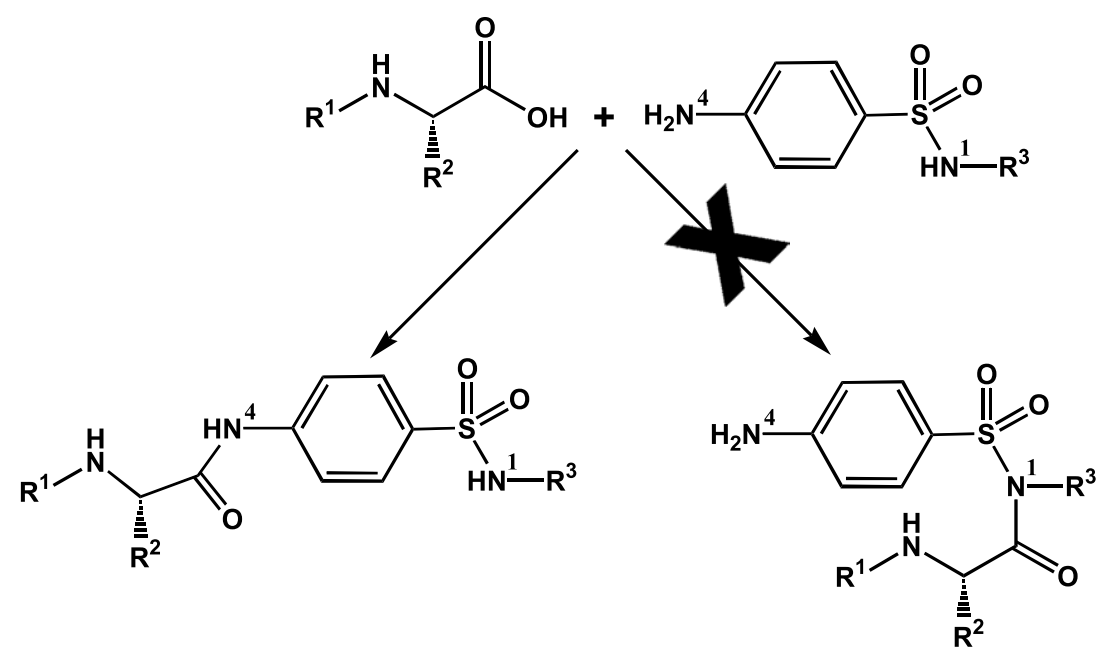


and proton or electron affinities. In the present work, the gas-phase acidity was calculated as:

$\Delta G^{\circ}=\Delta H^{\circ}-T \Delta S^{\circ}$

with the enthalpic difference $\left(\Delta H^{\circ}\right)$ associated to the reaction SULFA-H $\rightarrow$ SULFA $^{-}+\mathrm{H}^{+}$given as:

$\Delta H^{\circ}=H^{\circ}\left(\mathrm{SULFA}^{-}\right)+H^{\circ}\left(\mathrm{H}^{+}\right)-H^{\circ}(\mathrm{SULFA}-\mathrm{H})$

This equation may be simplified to

$\Delta H^{\circ}=H^{\circ}\left(\mathrm{SULFA}^{-}\right)-H^{\circ}(\mathrm{SULFA}-\mathrm{H})+5 / 2 R T$

since the enthalpy of the proton is reduced to the sum of the contributions from translational motion $\left(H_{\mathrm{T}}=3 / 2 R T\right)$ and from the $p V$ term. The gas-phase acidity computed with the combined strategy (BL and BS basis sets) for $p$-aminobenzenesulfonamide was tested against the gas-phase acidity obtained with the B3LYP/6-311+G(2d,2p) approach; the two results differ by only $0.1 \mathrm{~kJ} / \mathrm{mol}$.

\section{Results and discussion}

\subsection{Effects of $\mathbf{R}^{1}$ and $\mathbf{R}^{2}$ on sulfonamide acidity}

In a previous experimental and theoretical work we found that the acylation of four different para-aminobenzenesulfonamides with glycine was regiosselective and governed by a combination of geometrical, thermodynamic and electronic factors. ${ }^{13}$ These findings drove us to the present study, where the influence of the sulfonamido group acidity on chemical reactivity and other sulfonamide properties is discussed. We analyzed separately the effects on sulfonamido acidity of: (i) the $\mathrm{R}^{1}$ group (para-aryl substituent) and, (ii) the $\mathrm{R}^{2}$ group attached to $\mathrm{N}^{1}(3)$. We chose groups that were either present in bioactive sulfonamides or useful to establish structure-activity relationships (SAR).

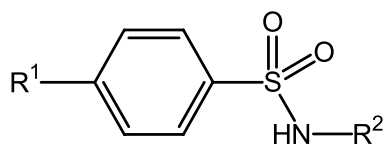

3

In Table 1, a compilation of the most interesting geometric parameters is reported for several different para- $\mathrm{R}^{1}$ benzenesulfonamides, with $\mathrm{R}^{1}=\mathrm{H}, \mathrm{F}, \mathrm{Cl}, \mathrm{OH}, \mathrm{CN}, \mathrm{NH}_{2}$, $\mathrm{NO}_{2}, \mathrm{CH}_{3}$ and $\mathrm{OCH}_{3}$. The $\mathrm{R}^{1}$ substituents were chosen in such a way that a wide range of Hammett constants could be spanned, allowing us to analyse the effect of varying substituents from those having large electron withdrawing effects to those with large electron donation capacity. A close inspection of parameters given in Table 1 shows that the length of the $\mathrm{N}-\mathrm{H}$ bond that may suffer heterolytic cleavage upon acylation with amino acids is unaffected by the electronic effects imposed by the different $\mathrm{R}^{1}$ groups tested. This is also the case for the $\mathrm{S}=\mathrm{O}$ bond lengths, which vary between 1.466 and $1.470 \AA$. This is in clear contrast with the significantly larger variations found for the ring-sulfur bond lengths. Such behavior suggests that only the sulfur atom is largely affected by the presence of different groups attached to the aromatic ring at the para position, leaving the oxygen atoms lessly affected. When compared with $\mathrm{R}^{1}=\mathrm{H}$, electron donating groups such as $\mathrm{NH}_{2}$ lead to an increase in the $\mathrm{S}=\mathrm{O}$ and $\mathrm{S}-\mathrm{N}$ bond lengths, and to a decrease in the $\mathrm{Ar}-\mathrm{S}$ distance. The opposite is found for $\mathrm{R}^{1}=\mathrm{NO}_{2}$, where $\mathrm{S}=\mathrm{O}$ and $\mathrm{S}-\mathrm{N}$ bonds are shortened and the $\mathrm{Ar}-\mathrm{S}$ bond length is enlarged. In all compounds studied, the non-planar $\mathrm{O}=\mathrm{S}=\mathrm{O}$ group is cis-oriented with the $\mathrm{H}-\mathrm{N}^{1}-\mathrm{H}^{\prime}$ bonds. The small influence of the $\mathrm{R}^{1}$ substituent on the sulfonamido group is also noticed from the slight variation in the $\mathrm{H}-\mathrm{N}^{1}-\mathrm{S}-\mathrm{H}^{\prime}$ dihedral angle, which varies between 121.7 and $123.8^{\circ}$ for $\mathrm{R}^{1}=\mathrm{NH}_{2}$ and $\mathrm{R}^{1}=$ $\mathrm{NO}_{2}$, respectively.

Table 1 also displays the enthalpies of inversion for the different compounds considered, calculated as the difference between the enthalpy at $T=298.15 \mathrm{~K}$ for the fullyoptimized $\mathrm{H}-\mathrm{N}^{1}-\mathrm{H}^{\prime}$ trans-oriented geometry and that for the $\mathrm{H}-\mathrm{N}^{1}-\mathrm{H}^{\prime}$ cis-oriented species. The values lie in the 2.8$4.9 \mathrm{~kJ} / \mathrm{mol}$ range, respectively, for $\mathrm{NH}_{2}$ and $\mathrm{NO}_{2}$ groups, and are correlated with the calculated $\mathrm{S}-\mathrm{N}$ bond lengths. Indeed, the shorter $\mathrm{S}-\mathrm{N}$ bond in the nitro-substituted compound is responsible for a less effective accommodation of the nitrogen atom lone-pair, when compared to its aminosubstituted counterpart, thus explaining the different enthalpies of inversion found.

Gas-phase acidities calculated as $\Delta G^{\circ}$ at the B3LYP/6$311+\mathrm{G}(2 \mathrm{~d}, 2 \mathrm{p}) / / \mathrm{B} 3 \mathrm{LYP} / 6-31+\mathrm{G}(\mathrm{d})$ level of theory, are also reported in Table 1 . This thermodynamic property is a direct measure of the promptness of the sulfonamido group to lose one proton during the acylation reaction. The $\Delta G^{\circ}$ calculated for the nine different $\mathrm{R}^{1}$-substituted sulfonamides show that, despite the large intramolecular distance between the para-substituent and the sulfonamido group, this

Table 1. Selected geometrical parameters, enthalpies of inversion and gas-phase acidities of benzenesulfonamides substituted at the $\mathrm{R}^{1}$ position computed at the B3LYP//6-311+G(2d,2p)//B3LYP/6-31+G(d) level of theory

\begin{tabular}{|c|c|c|c|c|c|c|}
\hline \multirow[t]{2}{*}{$\mathrm{R}^{1}\left(\mathrm{R}^{2}=\mathrm{H}\right)$} & \multicolumn{4}{|l|}{ Geometrical parameters $(\AA)$} & \multirow{2}{*}{$\begin{array}{l}\Delta H^{\circ}(\mathrm{kJ} / \mathrm{mol}) \\
\text { Inversion }\end{array}$} & \multirow{2}{*}{$\begin{array}{l}\Delta G^{\circ}(\mathrm{kJ} / \mathrm{mol}) \\
\text { Acidity }\end{array}$} \\
\hline & $\mathrm{d}(\mathrm{S}=\mathrm{O})$ & $\mathrm{d}(\mathrm{Ar}-\mathrm{S})$ & $\mathrm{d}(\mathrm{S}-\mathrm{N})$ & $\mathrm{d}(\mathrm{N}-\mathrm{H})$ & & \\
\hline$-\mathrm{H}$ & $1.468 / 1.468(1.488 / 1.500)$ & $1.797(1.842)$ & $1.700(1.582)$ & $1.018(1.024)$ & 3.6 & 1402.8 \\
\hline$-\mathrm{F}$ & $1.468 / 1.468(1.488 / 1.500)$ & $1.794(1.843)$ & $1.700(1.580)$ & $1.019(1.024)$ & 4.4 & 1391.4 \\
\hline$-\mathrm{Cl}$ & $1.468 / 1.468(1.487 / 1.499)$ & $1.796(1.843)$ & $1.699(1.580)$ & $1.019(1.024)$ & 4.2 & 1385.2 \\
\hline$-\mathrm{OH}$ & $1.469 / 1.469(1.489 / 1.502)$ & $1.788(1.843)$ & $1.702(1.580)$ & $1.019(1.024)$ & 3.6 & 1407.2 \\
\hline$-\mathrm{CN}$ & $1.467 / 1.467(1.486 / 1.497)$ & $1.803(1.840)$ & $1.695(1.579)$ & $1.019(1.024)$ & 4.7 & 1361.1 \\
\hline$-\mathrm{NH}_{2}$ & $1.470 / 1.470(1.490 / 1.502)$ & $1.783(1.841)$ & $1.705(1.581)$ & $1.019(1.024)$ & 2.8 & 1421.9 \\
\hline$-\mathrm{NO}_{2}$ & $1.466 / 1.466(1.484 / 1.496)$ & $1.804(1.834)$ & $1.693(1.581)$ & $1.018(1.024)$ & 4.9 & 1352.2 \\
\hline$-\mathrm{CH}_{3}$ & $1.469 / 1.469(1.489 / 1.501)$ & $1.793(1.841)$ & $1.702(1.582)$ & $1.019(1.024)$ & 3.6 & 1404.3 \\
\hline$-\mathrm{OCH}_{3}$ & $1.470 / 1.469(1.489 / 1.502)$ & $1.787(1.841)$ & $1.703(1.581)$ & $1.019(1.024)$ & 3.5 & 1411.0 \\
\hline
\end{tabular}

Geometrical parameters given in parenthesis refer to the corresponding anionic forms. 
property is largely affected by the nature of $\mathrm{R}^{1}$. This is clearly depicted in Fig. 1(a), where the calculated $\Delta G^{\circ}$ are plotted against the Hammett $\sigma$ constants for the different $\mathrm{R}^{1}$ employed. ${ }^{37}$ A clear correlation is observed $\left(r^{2}=0.94\right)$, showing that the calculated $\Delta G^{\circ}$ strongly depend on the electronic effects of the nine $\mathrm{R}^{1}$ substituents studied. This dependence is reflected by free energy differences as high as $70 \mathrm{~kJ} / \mathrm{mol}$, found between the para-amino- and the paranitrobenzenesulfonamides. This is an extremely important finding, since it shows that substitution at $\mathrm{R}^{1}$ is also responsible for the different acidities that characterize sulfonamide-based drugs.

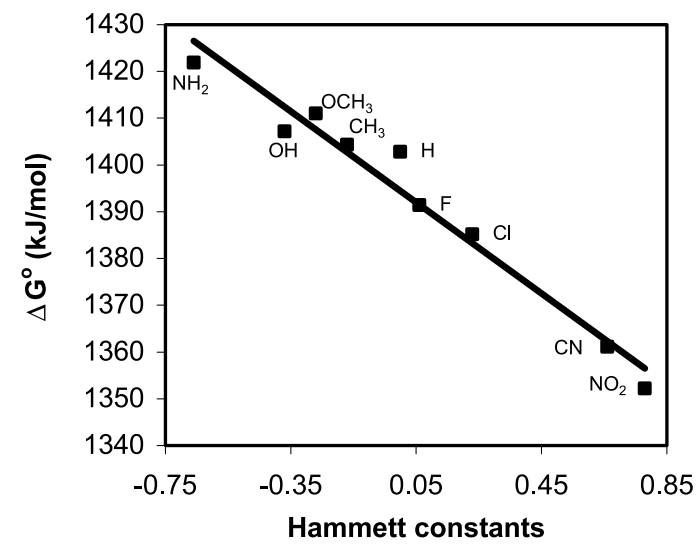

(a)

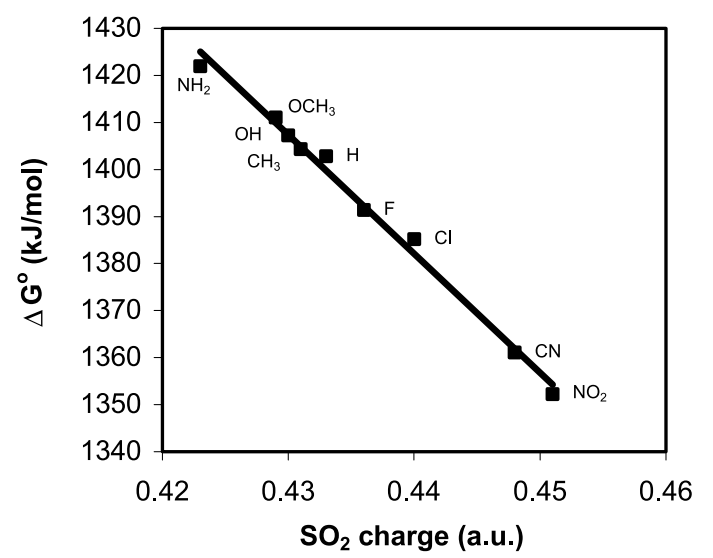

(b)

Figure 1. Correlation between calculated gas-phase acidities (as $\Delta G^{\circ}$ ) of $\mathrm{R}^{1}-\mathbf{3}$ compounds and (a) Hammett $\sigma$ constants for the $\mathrm{R}^{1}$ substituent; (b) the charge in the $\mathrm{SO}_{2}$ group.

Depending on the substituent considered, calculated charges at the sulfonamido group and derived from a Natural Population Analysis ${ }^{38}$ show larger variations in oxygen and sulfonamido hydrogen atoms than in nitrogen and sulfur. In an earlier work of Bell et al. ${ }^{4}$ concerning only $\mathrm{N}^{1}$-substituted sulfanilamides, $\mathbf{1}$, an increase of the compound acidity (which is equivalent to a decrease in $\Delta G^{\circ}$ ) was found to cause a decrease in the $\mathrm{SO}_{2}$ group negative charge and in bacteriostatic activity. The variation of calculated $\Delta G^{\circ}$ with the charge of the $\mathrm{SO}_{2}$ group is depicted in Fig. 1(b). As it can be seen, the correlation between sulfonamide $\Delta G^{\circ}$ and the atomic populations at the
$\mathrm{SO}_{2}$ group determined by the para-substituent of the aromatic ring is now linear $\left(r^{2}=0.99\right)$. This shows that direct substitution in the aromatic ring has also a great effect in the charge of the sulfonamido group that is highly correlated with the electronic effects caused by the substituent.

In a recent work, Soriano-Correa et al. ${ }^{8}$ suggested that sulfonamide activity was accompanied by a small torsion barrier, i.e. more rigid molecules will be more active. In order to check the rigidity of sulfonamide, the energetics of the rotation of the aromatic ring with respect to the sulfonamido group was calculated for sulfanilamide and is depicted in Fig. 2. At the B3LYP/6-31+G(d) level of theory, the calculated energy barrier is of about $8.5 \mathrm{~kJ} / \mathrm{mol}$, slightly lower than for $\mathrm{C}-\mathrm{C}$ rotation in ethane $(\sim 12 \mathrm{~kJ} /$ mol). This suggests almost free rotation around the $\mathrm{Ar}-\mathrm{S}$ bond, despite the neighboring oxygen atoms of the sulfonamido group. The calculated energy of rotation will be valid for the generality of sulfanilamides since substitution at both $\mathrm{R}^{1}$ and $\mathrm{R}^{2}$ positions will not sterically affect the ring-S bond rotation.

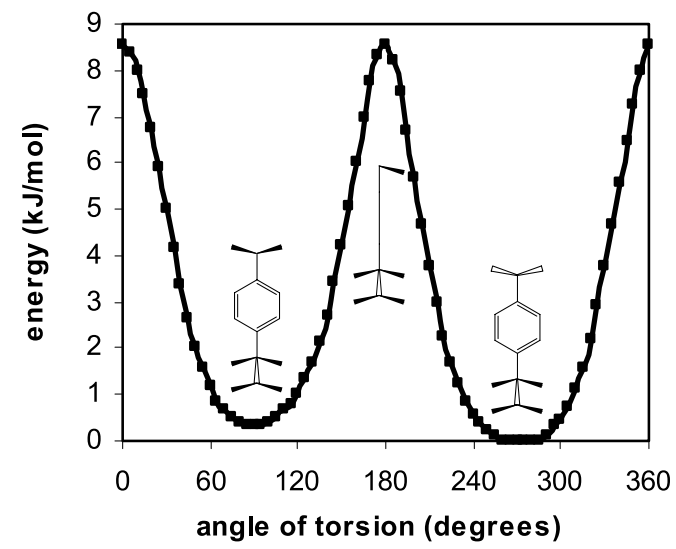

Figure 2. Potential energy surface for the rotation of the phenyl ring around the ring-S axis calculated at the B3LYP/6-31+G(d) level of theory. The $\mathrm{X}$-axis values of 0 and $180^{\circ}$ mean that the aromatic ring lies between the $\mathrm{SO}_{2}$ moiety.

As mentioned above, despite the large distance between $\mathrm{R}^{1}$ and $\mathrm{N}^{1}$ positions, the $\mathrm{R}^{1}$ substituent seems to have a crucial role in the acidities of sulfonamide derivatives. An enhanced effect in the chemical and biological properties that distinguish different sulfonamide-based drugs should be expected if $\mathrm{N}^{1}$ substitution takes place due to its proximity to the leaving proton. Thus, the role of different $\mathrm{R}^{2}$ groups attached to the $\mathrm{N}^{1}$ atom should be equally inspected. In view of this, we analyzed the influence of several different $R^{2}$ substituents on the structure of the sulfonamido group, as reported in Table 2. The substituents were chosen taking into account the structures of some sulfonamide-based drugs, with the difference that the para-amino group is now absent. In comparison with data from Table 1, larger changes in the internal geometry of the sulfonamido group are now observed, as expected from the closer distance between the substituent group and the sulfur atom. First, if an oxygen atom is placed in a position adjacent to the carbon-sulfonamido nitrogen bond (two last entries in Table 2 ), the $\mathrm{S}-\mathrm{N}$ bond length is noticeably increased when 
Table 2. Selected geometrical parameters and gas-phase acidities of benzenesulfonamides substituted at the $\mathrm{R}^{2}$ position computed at the B3LYP//6-311+ $\mathrm{G}(2 \mathrm{~d}, 2 \mathrm{p}) / / \mathrm{B} 3 \mathrm{LYP} / 6-31+\mathrm{G}(\mathrm{d})$ level of theory

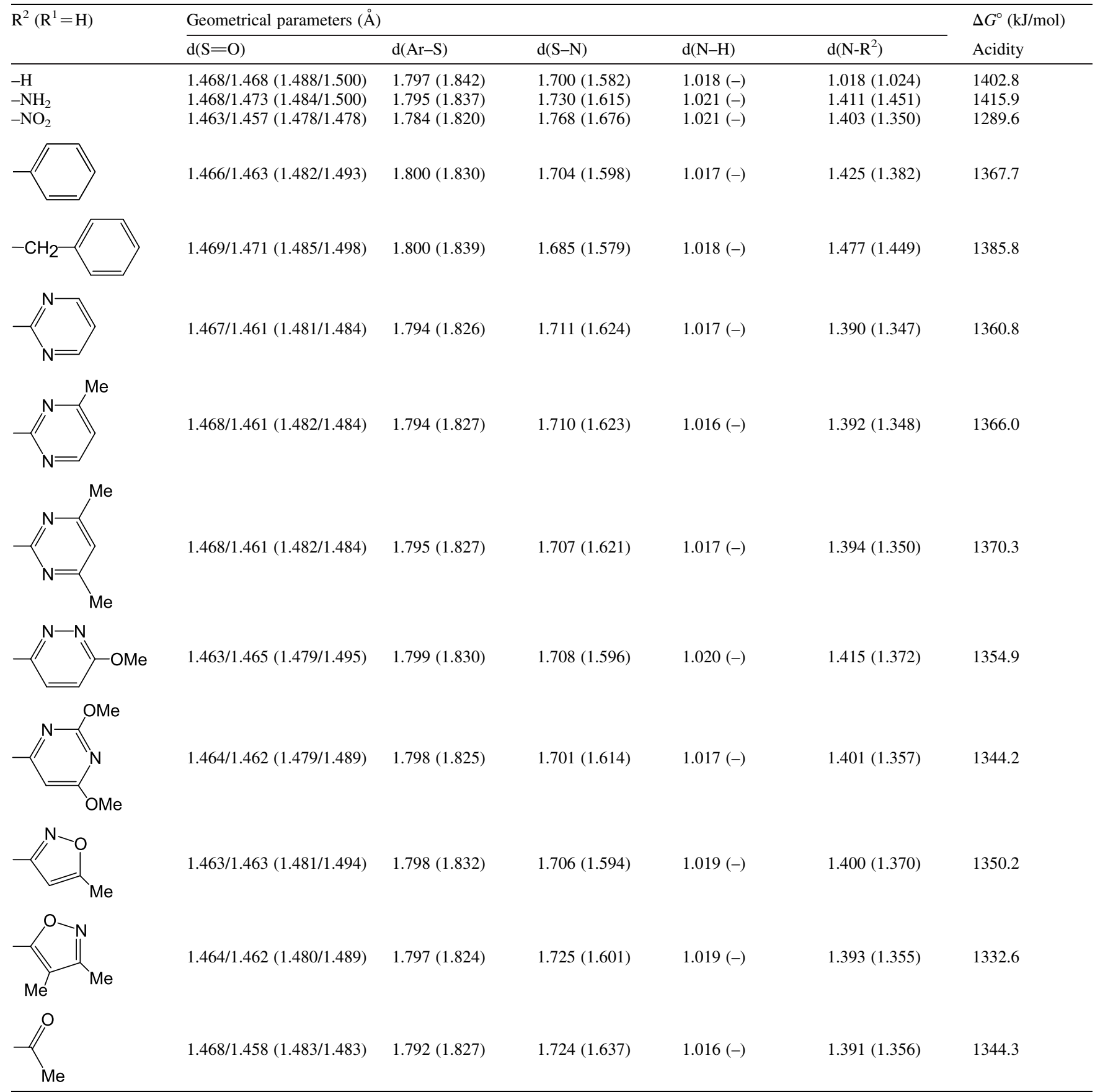

Geometrical parameters given in parenthesis refer to the corresponding anionic forms.

compared to that in benzenesulfonamide. Second, in the case of a nitrogen atom placed in a position adjacent to the carbon-sulfonamido nitrogen bond, the $\mathrm{S}-\mathrm{N}$ bond is less changed if donor groups are attached to the heterocyclic ring. This is easily noticed for sulfadiazine, sulfamerazine and sulfamethazine derivatives, entries 6-8 in Table 2, where a slight increase in the $\mathrm{S}-\mathrm{N}$ bond is found when on going from the sulfamethazine to the sulfadiazine derivative followed by correspondent slight decrease in the $\mathrm{N}-\mathrm{R}^{2}$ bond length.

For the list of compounds reported in Table 2, the variation of calculated $\Delta G^{\circ}$ with the charge of the $\mathrm{SO}_{2}$ group is depicted in Fig. 3(a). In this case, the correlation between acidity and charge is not linear, which suggests a rather different influence caused by the substituent in sulfonamide acidity. The variation $\Delta G^{\circ}$ (sulfadiazine) $<\Delta G^{\circ}$ (sulfamera(sulfamerazine) $<\Delta G^{\circ}$ (sulfamethazine) is associated with a negligible decrease in the positive charge calculated for the $\mathrm{SO}_{2}$ group ( $0.487 ; 0.486 ; 0.483$ a.u., respectively). These differences in the $\mathrm{SO}_{2}$ group charge do not seem to be the only cause for a $6 \mathrm{~kJ} / \mathrm{mol}$ variation in $\Delta G^{\circ}$ between sulfadiazine and sulfamerazine derivatives, or for $4 \mathrm{~kJ} / \mathrm{mol}$ between the sulfamerazine and sulfamethazine derivatives, 


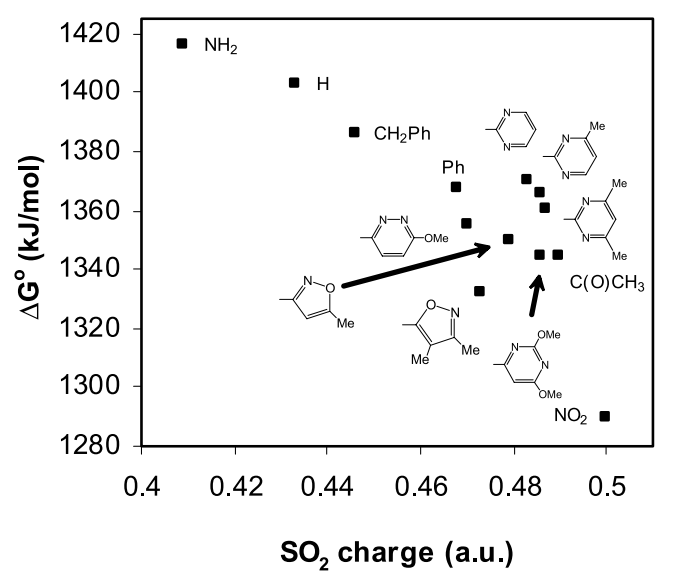

(a)

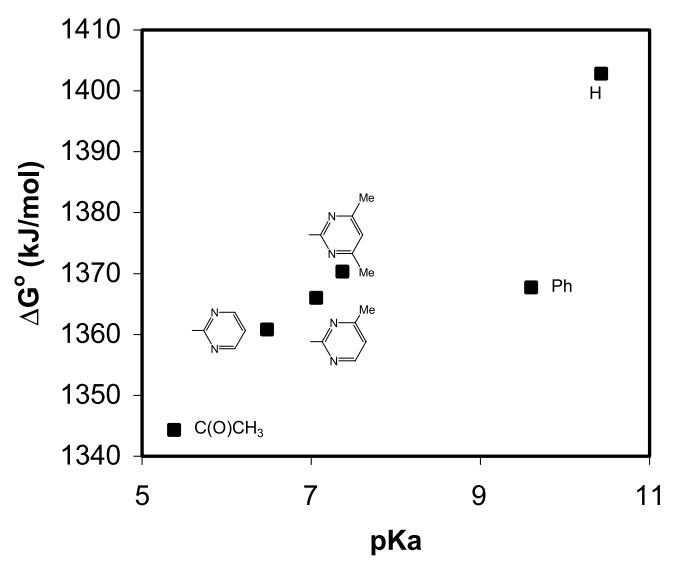

(b)

Figure 3. Correlation between calculated gas-phase acidities (as $\Delta G^{\circ}$ ) of $\mathrm{R}^{2}-\mathbf{3}$ compounds and (a) the charge in the $\mathrm{SO}_{2}$ group; (b) experimental $\mathrm{pK}_{\mathrm{a}}$ 's of the parent sulfa drugs, as reported in Ref. 4.

since the small charge variation is connected with a larger $\Delta G^{\circ}$ variation. Further, if we consider the sulfamethoxypyridazine and sulfadimethoxine derivatives, both incorporating methoxyl groups attached to the aromatic ring, a $\Delta G^{\circ}$ difference of $\sim 10 \mathrm{~kJ} / \mathrm{mol}$ is now accompanied by a larger variation in the $\mathrm{SO}_{2}$ group charges, 0.470 and 0.486 a.u. for sulfamethoxypyridazine and sulfadimethoxine derivatives, respectively. Also important and contrarily to what was found for sulfadiazine and methyl substituted sulfadiazine derivatives, the decrease in $\Delta G^{\circ}$ is now associated with a decrease in the S-N bond length. Finally, the difference between NPA charges in the $\mathrm{SO}_{2}$ moiety calculated for sulfamethoxypyridazine and sulfadimethoxine derivatives is identical to the difference found for sulfadimethoxine and the $\mathrm{NO}_{2}$-substituted sulfonamide derivatives that correspond to variations in $\Delta G^{\circ}$ of 10 and $55 \mathrm{~kJ} / \mathrm{mol}$, respectively. Thus, and as observed for $\mathrm{R}^{1}$ substituents, the charge on the $\mathrm{SO}_{2}$ group cannot be seen as the only factor affecting sulfonamide acidity. Therefore, a conjugation of geometrical and electronic effects determined by the $R^{1}$ and $R^{2}$ substituents, including delocalization through aromatic rings on either side of the $\mathrm{SO}_{2}$ group, must underlie sulfonamide reactivity and bioactivity. This should be interpreted as an addition, and not a correction, to the suggestions of Bell et al. ${ }^{4}$

It is noteworthy that the computed acidities herein reported present some correlation with previously published $\mathrm{pK}_{\mathrm{a}}$, as shown in Fig. 3(b). In fact, if we do not consider the phenyl derivative, there is a linear correlation, which gives support to the quality of the computed thermodynamic data reported in the present work. Following conclusions by Bell et al. ${ }^{4}$ these data have implications in terms of correlation with bacteriostatic activity. Indeed, computed acidities for compounds considered in Fig. 3(b) are somewhat correlated with the bacteriostatic activities against $E$. coli reported by the same authors (data not shown). ${ }^{4}$ However, the correlation is not perfect, as one should expect from the fact that linear correlations have only been found for series of homologous sulfonamides. $4,39,40$

The present work is also relevant for sulfonamide therapeutical properties other than bacteriostatic activity. Aromatic sulfonamides used to treat glaucoma are known to exhert their therapeutical action through inhibition of the human zinc-enzyme carbonic anhydrase II (HCA II). These sulfonamides bind the zinc dication of HCA II through their deprotonated sulfonamide nitrogen, thus $-\mathrm{SO}_{2} \mathrm{NH}$ - acidity has an important role on sulfonamide ability to inhibit HCA II. Indeed, recent studies by Remko and co-workers show that the acidity of common sulfa drugs such as acetazolamide, brinzolamide and dorzolamide is correlated with their $\mathrm{Zn}^{2+}$-binding affinity. ${ }^{41,42}$

\subsection{Implications of sulfonamide reactivity on prodrug design}

As above mentioned, this study was set out to shed some light on the understanding of the $\mathrm{N}^{1}$ versus $\mathrm{N}^{4}$ acylation reaction between glycine and four different para-aminobenzenesulfonamides, previously reported. ${ }^{13}$ In the present notation, acylation at position $\mathrm{N}^{1}$ means reaction at the sulfonamido group while acylation at the $\mathrm{N}^{4}$ nitrogen means reaction at the 4-anilino group. Experimentally, sulfamethazine, sulfamethoxypyridazine, sulfadimethoxine and sulfisoxazole were reacted with $\mathrm{N}^{\alpha}$-protected glycine, and both the position and yield of acylation were seen to vary with sulfonamide. The yields of $\mathrm{N}^{4}$-acylation with $\mathrm{N}^{\alpha}$-BocGlyOH were $52 \%, 43 \%$ and $41 \%$ for the three first compounds, respectively (Table 3 ). For sulfisoxazole, high levels of starting materials were recovered, although the formation of several products could be detected. $\mathrm{N}^{\alpha}-\mathrm{ZGlyOH}$ was also reacted with sulfamethazine and sulfisoxazole, for comparison purposes. Again, reaction with sulfamethazine yielded $41 \%$ of the $\mathrm{N}^{4}$-derivative, whereas reaction with sulfisoxazole yielded a complex mixture from which $8 \%$ of the $\mathrm{N}^{1}$-derivative could be isolated. Thus, it was proposed that sulfisoxazole reacts both at $\mathrm{N}^{1}$ and $\mathrm{N}^{4}$ with very low yields for both reactions. These experimental observations seem to be directly correlated with the acidity of these four sulfas. Data on Table 3 show that $\Delta G^{\circ}$ decreases from sulfamethazine to sulfisoxazole, which comes associated with a decrease in $\mathrm{N}^{4}$-acylation yields. Further, lower $\Delta G^{\circ}$ values are correlated with lower energetic barriers for $\mathrm{N}^{1}$-acylation. This shows that, as the sulfonamide gets more acidic, the easier becomes the 
Table 3. Correlation between gas-phase acidity in the sulfonamido group and published experimental yields of $\mathrm{N}^{4}$-acylation and enthalpies for $\mathrm{N}^{1}$-acylation

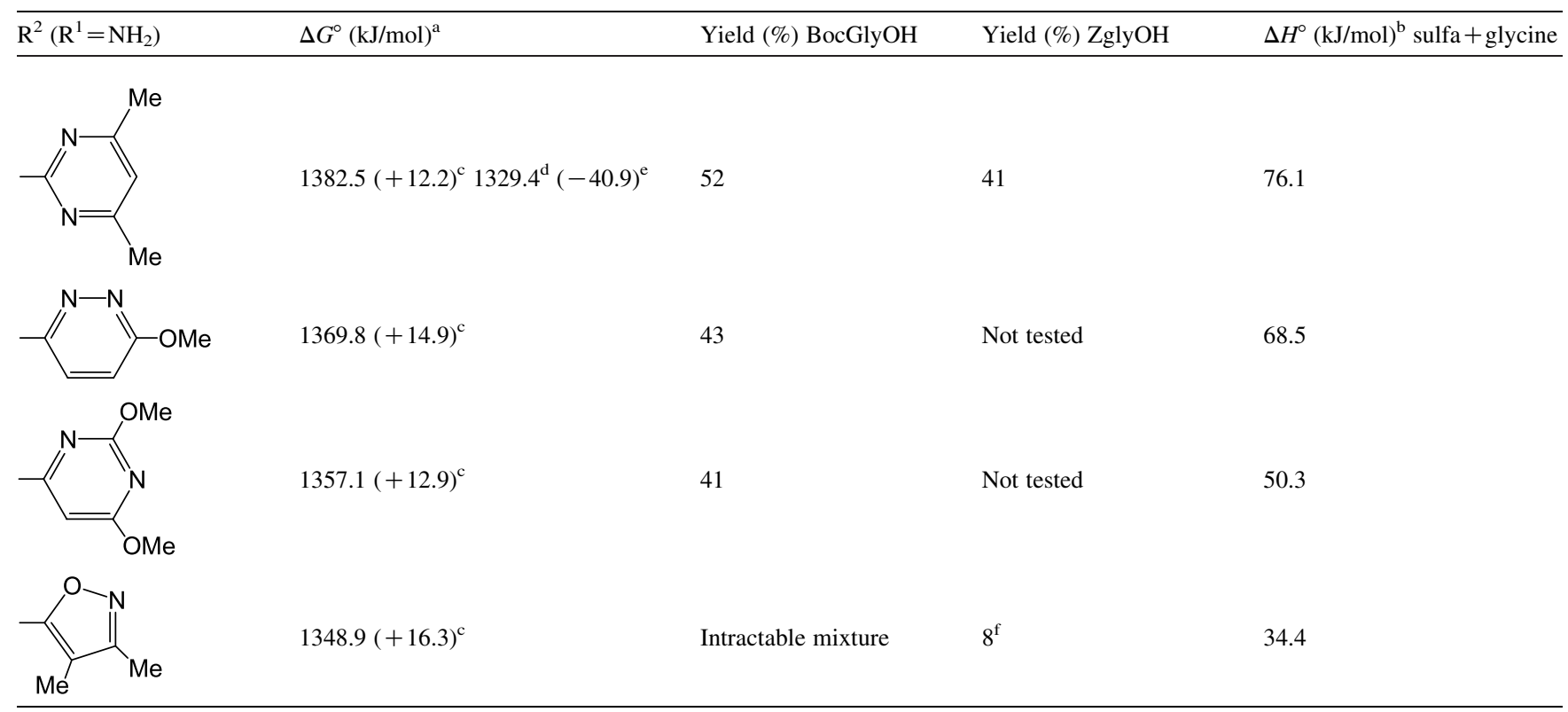

${ }^{a} B 3 L Y P / / 6-311+G(2 d, 2 p) / / B 3 L Y P / 6-31+G(d)$.

${ }^{\mathrm{b}}$ B3LYP//6-311+G(d,p)//B3LYP/6-31+G(d).

${ }^{c}$ Difference between $\mathrm{R}^{1}=\mathrm{NH}_{2}$ and $\mathrm{R}^{1}=\mathrm{H}$ compounds.

${ }^{\mathrm{d}} \mathrm{R}^{1}=\mathrm{NO}_{2}$.

${ }^{\mathrm{e}}$ Difference between $\mathrm{R}^{1}=\mathrm{NO}_{2}$ and $\mathrm{R}^{1}=\mathrm{H}$ compounds.

${ }^{\mathrm{f}} \mathrm{N}^{1}$-acylation product.

introduction of an amino acid or peptide carrier at the sulfonamido group $\left(\mathrm{N}^{1}\right)$.

These findings have obvious implications for the design of peptide-based sulfonamide prodrugs. The higher acidity of the $-\mathrm{SO}_{2} \mathrm{NH}-$ group with respect to the $-\mathrm{NH}_{2}$ group reflects the relative stabilities of the corresponding conjugate bases. From the higher stability of $\mathrm{SO}_{2} \mathrm{~N}^{-}$with respect to $-\mathrm{NH}^{-}$, together with the higher steric compression around the $\mathrm{N}^{1}$ atom, one expects the sulfonamide to behave as a better leaving group from an $\mathrm{N}^{1}$-acylsulfonamide than from an $\mathrm{N}^{4}$-acylsulfonamide. Indeed, all $\mathrm{N}^{4}$-acylsulfonamides derived from $\mathrm{N}^{\alpha}$-amino acids and dipeptides prepared in our laboratory were found to be useless as prodrugs, since they do not release the parent drug at physiological $\mathrm{pH}$ and temperature, with slow release being observed only under harsh conditions $\left(\mathrm{pH} 12,60{ }^{\circ} \mathrm{C}\right) .{ }^{43}$ Further, irreversible acylation at $\mathrm{N}^{4}$ blocks the first site of sulfonamide-enzyme interaction that underlies the bacteriostatic action of most sulfa drugs. ${ }^{1}$ This reinforces the importance of derivatizing sulfonamides at the $-\mathrm{SO}_{2} \mathrm{NH}-$ group to produce suitable prodrugs or novel drugs and, thus, the relevance of acidity studies on this class of compounds.

The difference between calculated $\Delta G^{\circ}$ for sulfonamide derivatives reported in Table 1 and their parent sulfas listed in Table 3 , i.e. $\mathrm{R}^{1}=\mathrm{NH}_{2}$ and $\mathrm{R}^{1}=\mathrm{H}$ compounds, is also shown in Table 3 . In the case of sulfamethazine, the calculated $\Delta G^{\circ}$ value for the compound with $\mathrm{R}^{1}=\mathrm{NO}_{2}$ is also given. The differences show that the para-amino still increases $\Delta G^{\circ}$ while the para-nitro group decreases its value. Further, when $R^{2}$ is not equal to $H$ the differences in acidity are slightly decreased but, importantly, its effects on the final computed acidity follow the same direction as given by the values compiled in Table 1. Thus, the Hammett $\sigma$ constants may be extremely useful for the future design of sulfa drugs with tailored acidities.

\section{Conclusions}

This theoretical study was set out to analyze the determinants of sulfonamide acidity and the influence of the latter on sulfonamide reactivity towards acylating agents, such as amino acids. To achieve our purposes, DFT calculations, based on the B3LYP method, were carried out to fully optimize the geometry of all compounds under study and to extract their enthalpies at $T=298.15 \mathrm{~K}$. These enthalpies were then used to compute gas-phase acidities of the sulfonamides. The main conclusions that can be withdrawn from the present work are:

i. There is a linear correlation between sulfonamide acidity and the Hammett constants of substituents at the para-aryl position.

ii. Sulfonamide acidity was found to be linearly correlated with the charge of the $\mathrm{SO}_{2}$ group in the case of para-aryl substitution in agreement with previously reported works, whereas a conjugation of steric and electronic factors determined by the $\mathrm{N}^{1}$-substituent seems to govern sulfonamide acidity.

iii. The acidity of the sulfonamido group was found to be correlated with the reactivity of some sulfa drugs towards amino acids as acylating agents.

iv. The dipeptide carrier approach to design the sulfonamide prodrugs will expectedly be more successful with more acidic sulfas.

v. Hammett constants may be useful indicators for the design of sulfonamides with tailored acidities. 


\section{Acknowledgements}

The authors thank Professor Rui Moreira (University of Lisbon) for fruitful discussions. Thanks are due to Fundação para a Ciência e a Tecnologia, F.C.T., Lisbon, Portugal, for financial support through research unit Centro de Investigação em Química of the University of Porto and through POCTI/FCB/39218/2001. J.R.B.G. thanks F.C.T. for the award of a post-doctoral (SFRH/BPD/11582/2002) research grant.

\section{References and notes}

1. Anand, N. Sulfonamides and Sulfones. In Burger's Medicinal Chemistry and Drug Discovery; Wolff, M. E., Ed.; Therapeutic Agents; Wiley: New York, 1996; Vol. 2, pp 527-544.

2. Martindale: The Extra Pharmacopæia, 31st ed.; Reynolds, J. E. F., Ed.; The Royal Pharmaceutical Society: London, 1996.

3. Silverman, R. B. The Organic Chemistry of Drug Design and Drug Action; Academic: London, 1992.

4. Bell, P. H.; Roblin, R. O. J. Am. Chem. Soc. 1942, 64, 2905.

5. Kumler, W. D.; Strait, L. A. J. Am. Chem. Soc. 1943, 65, 2349.

6. Kumler, W. D.; Daniels, T. C. J. Am. Chem. Soc. 1943, 65, 2190.

7. Seydel, J. K. Pharm. Sci. 1968, 57, 1455.

8. Soriano-Correa, C.; Esquivel, R. O.; Sagar, R. P. Int. J. Quant. Chem. 2003, 94, 165.

9. Remko, M.; von der Lieth, C.-W. Bioorg. Med. Chem. 2004, 12, 5395-5403.

10. Plosker, G. L.; Tavish, D. Drugs 1994, 47, 622.

11. Kaur, I. P.; Singh, M.; Kanwar, M. Int. J. Pharm. 2000, 199, 119.

12. Famaey, J. P. Inflamm. Res. 1997, 46, 437.

13. Gomes, P.; Gomes, J. R. B.; Rodrigues, M.; Moreira, R. Tetrahedron 2003, 59, 7473.

14. Gomes, P.; Santos, M. I.; Trigo, M. J.; Castanheiro, R. Synth. Commun. 2003, 33, 1683.

15. Bai, J. P.; Hu, M.; Subramanian, P.; Mosberg, H. I.; Amidon, G. L. J. Pharm. Sci. 1992, 81, 113.

16. Anand, B. S.; Patel, J.; Mitra, A. K. J. Pharmacol. Exper. Therapeutics 2002, 304, 781.

17. Purdie, J. E.; Benoiton, N. L. J. Chem. Soc., Perkin Trans. 2 1973, 1845.

18. Capasso, S.; Vergara, A.; Mazzarella, L. J. Am. Chem. Soc. 1998, 120, 1990.

19. Goolcharran, C.; Borchardt, R. T. J. Pharm. Sci. 1998, 87, 283.

20. Wallace, J. L.; Bak, A.; Knight, W.; Asfaha, S.; Sharkey, K. A.; MacNaughton, W. K. Gastroenterology 1998, 115, 101.

21. Scozzafava, A.; Owa, T.; Mastrolorenzo, A.; Supuran, C. T. Curr. Med. Chem. 2003, 10, 925.

22. Supuran, C. T.; Innocenti, A.; Mastrolorenzo, A.; Scozzafava, A. Mini-Rev. Med. Chem. 2004, 4, 189.
23. Becke, A. D. Phys. Rev. A 1988, 38, 3098-3100.

24. GAMESS-US Version 14/01/2003 (R3), Schmidt, M. W.; Baldridge, K. K.; Boatz, J. A.; Elbert, S. T.; Gordon, M. S.; Jensen, J. H.; Koseki, S.; Matsunaga, N.; Nguyen, K. A.; Su, S. J.; Windus, T. L.; Dupuis, M.; Montgomery, J. A. J. Comput. Chem. 1993, 14, 1347.

25. Frisch, M. J.; Trucks, G. W.; Schlegel, H. B.; Scuseria, G. E.; Robb, M. A.; Cheeseman, J. R.; Zakrzewski, V. G.; Montgomery, J. A., Jr.; Stratmann, R. E.; Burant, J. C.; Dapprich, S.; Millan, J. M.; Daniels, A. D.; Kudin, K. N.; Strain, M. C.; Farkas, O.; Tomasi, J.; Barone, V.; Cossi, M.; Cammi, R.; Mennucci, B.; Pomelli, C.; Adammo, C.; Clifford, S.; Ochterski, J.; Petersson, G. A.; Ayala, P. Y.; Cui, G.; Morokuma, K.; Malick, D. K.; Rabuck, A. D.; Raghavachari, K.; Foresman, J. B.; Cioslowski, J.; Ortiz, J. V.; Stefanov, B. B.; Liu, G.; Liashenko, A.; Piskorz, P.; Komaromi, I.; Gomperts, R.; Martin, R. L.; Fox, D. J.; Keith, T.; Al-Laham, M. A.; Peng, C. Y.; Nanayakkara, A.; Gonzalez, C.; Challacombe, M.; Gill, P. M. W.; Johnson, B.; Chen, W.; Wong, M. W.; Andres, J. L.; Head-Gordon, M.; Replogle, E. S.; Pople, J. A. Gaussian 98, Revisions A.3, Gaussian, Inc.: Pittsburgh PA, 1998.

26. Lee, W.; Yang, R. G. Phys. Rev. B 1980, 37, 785-789.

27. Denis, P. A.; Ventura, O. N. Int. J. Quant. Chem. 2000, 80, 439-453.

28. Gomes, J. R. B.; Ribeiro da Silva, M. A. V. Inorg. Chem. Commun. 2003, 6, 149-153.

29. Gomes, J. R. B.; Ribeiro da Silva, M. A. V. J. Phys. Chem. A 2003, 107, 869-874.

30. Gomes, J. R. B.; Ribeiro da Silva, M. D. M. C.; Ribeiro da Silva, M. A. V. J. Phys. Chem. A 2004, 108, 2119-2130.

31. Ribeiro da Silva, M. A. V.; Lima, L. M. S. S.; Amaral, L. M. P. F.; Ferreira, A. I. M. C. L.; Gomes, J. R. B. J. Chem. Thermodyn. 2003, 35, 1343-1359.

32. Ribeiro da Silva, M. D. M. C.; Gomes, J. R. B.; Gonçalves, J. M.; Sousa, E. A.; Pandey, S.; Acree, W. E., Jr. J. Org. Chem. 2004, 69, 2785-2792.

33. Gomes, J. R. B.; Ribeiro da Silva, M. A. V. Int. J. Quant. Chem. 2005, 860-868.

34. Matos, M. A. R.; Miranda, M. S.; Morais, V. M. F.; Liebman, J. F. Org. Biomol. Chem. 2003, 1, 2566-2571.

35. Ribeiro da Silva, M. D. M. C.; Gomes, J. R. B.; Gonçalves, J. M.; Sousa, E. A.; Pandey, S.; Acree, W. E., Jr. Org. Biomol. Chem. 2004, 2, 2507-2512.

36. Morais, V. M. F.; Miranda, M. S.; Matos, M. A. R. Org. Biomol. Chem. 2003, 1, 4329-4334.

37. Hansch, C.; Leo, A.; Taft, R. W. Chem. Rev. 1991, 91, 165-195.

38. Reed, A. E.; Curtiss, L. A.; Weinhold, F. Chem. Rev. 1988, 88, 899-926.

39. Seydel, J. J. Med. Chem. 1971, 14, 724-729.

40. Cammarata, A.; Allen, R. C. J. Pharm. Sci. 1967, 56, 640-642.

41. Remko, M. J. Phys. Chem. A 2003, 107, 720-725.

42. Remko, M.; Garaj, V. Mol. Phys. 2003, 101, 2357-2368.

43. Moreira, R. Personal communication. 